\title{
Company Maturity Models: Application to Supplier Development Program in Oil \& Gas Sector
}

\author{
Jabier Retegi Albisua ${ }^{1,2}$ (D), Juan Ignacio Igartua López ${ }^{1}$ (DD \\ ${ }^{1}$ Mondragon Unibertsitatea (spain) \\ ${ }^{2}$ Orkestra - Basque Institute of Competitiveness (Spain) \\ jabier.retegi@gmail.com,jigartua@mondragon.edu
}

Received: November 2017

Accepted: February 2018

\begin{abstract}
:
Purpose: In order to achieve excellence, outsourced maintenance contractors in Oil\&Gas sector play a key role due to the important impact of their task on security, availability and energy consumption. This paper presents the process followed in order to implement a Supplier Development Program in a refinery using Company Maturity Model (CoMM) and the results obtained in three cases validating the method to obtain a strategic improvement project medium term grid.
\end{abstract}

Design/methodology/approach: The methodology followed consists of constructing a CoMM capturing the knowledge existing in the refinery and applying it with three supplier improvement teams. Findings and conclusions have arised through an observation of the three processes and extracting common conclusions.

Findings: The resulting CoMM has been used for self-assessment by three suppliers and has demonstrated its potential to define a medium-term improvement project road map validated by the customer. Furthermore, during the design and application processes, the contribution of CoMMs to the SECI process of knowledge management has been observed.

Practical implications: The use of CoMMs in a service contractor context can be applied in other sectors. It contributes to alignment of targets between the supplier and customer companies and to knowledge sharing inside both firms.

Originality/value: Maturity models in many transversal fields (CMMI, EFQM, BPMM, PEMM, etc.) have been thoroughly studied in the literature. Less effort has been made analysing the case of using maturity models constructed and implemented by a company for its specific purposes. In this paper, the process followed by a company to establish a Supplier Development Process using CoMMs is described.

Keywords: maturity, knowledge, oil, supplier, refinery, KM

\section{Introduction}

European refineries are going through a challenging period during the last years because of international competition and the rising effects of progressive low carbon economy. Global installed capacity is increasing while refinery number is decreasing. New refineries have more capacity and newer and more efficient technologies. Even more, energy and manpower costs are lower in other regions of the world than in Europe. From 2008 to 2015 , 54 refineries were closed in OECD countries and 19 in West Europe countries. 
This situation forces European refineries to intensely search for competitiveness. In spite of oil price and margin evolution, that means the need of new technologies installation that allows a better refinery configuration and the search of improvements in efficiency, particularly availability-utilization performance and energy efficiency. The need of excellence in refinery performance must be part of the culture of people working in the refinery. Irrespective of the affiliation of people, the need of being part of a unique task of transforming the site in a world class business must be shared by all workers.

This requirement of competitivity affects contractors executing maintenance activities which are directly involved in availability and utilization targets. Contractors should improve their service to allow the refinery to reach its targets and this evolution must be coherent with the changes happening inside the site.

That's why a Supplier Development process aiming to define a 3-year improvement project framework for the contractor is a necessary step to reach the targets. Of course, the definition of the projects to be developed must be made carefully to ensure the support to the efforts made inside the refinery in the transformation of the industrial culture and performance.

The aim of this article is to explain the project of applying CoMM methodology as a deployment of strategic targets and establishment of a supplier development process in line with it. The process was implemented in close cooperation with management staff of the refinery.

Furthermore, during the design and application processes of the CoMM, the contribution of CoMMs to the SECI process of knowledge management in an intercompany context has been observed.

\section{Literature Review}

Supplier development programs are usual in many sectors. Automotive companies started implementing those programs decades ago. In spite of several methodologies, the main intervention processes are well known.

This is not the case in Oil\&Gas sector. Supplier development programs implemented by big companies are not so common and are mainly oriented to regional development or social responsibility view and not so much to the specific target of competitive improvement.

Moreover, the special context of service suppliers needs a specific approach for the design of the supplier development program. The authors considered that Company Maturity Models could be a suitable method to implement an improvement process for the suppliers.

The maturity model method has been used during the last decades in order "to define directions, prioritize improvement opportunities and guide cultural changes" (Becker, Niehaves, Pöppelbuß \& Alexander, 2010). Maturity models have covered several aspects of the organizations as quality systems, maintenance, production management, human resources management and others. Maturity can be defined as "a measure to evaluate the capabilities of an organization in regards to a certain discipline" as presented by Rosemann and De Bruin (2005).

In Crosby (1979), a quality management maturity model establishing five stages in an organization's maturity and six measurement categories is proposed. In Maier, Moultrie and Clarkson (2012), a taxonomy of maturity grids is presented and a review of the main maturity models is listed specifying their description, process area and maturity levels.

Nevertheless, as Mettler (2011) indicates, the use of maturity models are criticized by some authors mainly because of their assumption that excellence can be directly achieved by the execution of the identified actions in each one of the maturity factors, or the overemphasis on the process perspective keeping aside employees' capabilities. Some authors as Biberoglu and Haddad (2002) estimate that maturity models are not sufficiently based on theoretical basis and that they rest on experiences that have demonstrated favorable results.

Pérez-Mergarejo, Pérez-Vergara and Rodríguez-Ruiz (2014) note that PEMM (Process and Enterprise Maturity Model) of Hammer (2007) could be the most suitable model to be applied to SMEs. This model has also been applied to big companies such as Michelin, Tetra Pak or Shell. 
Mc Cormack and Lockamy (2004) proposes a cross-sector supply chain management process maturity model and presents research findings that suggest a significant relationship between supply chain management maturity and performance.

Maturity models are a good source of potential ideas to implement in order to achieve good performance and an excellent way to make explicit the expectations an organization has towards its employees or its contractors. In order to avoid the objecions explained above, De Bruin, Freeze, Kulkarni and Rosemann (2005) establishes the phases to develop a maturity assessment model that include a design phase with several sources of knowledge and a testing phase.

During this project, a better coordination between the customer and supplier companies was also to be improved. In order to improve this target, it was necessary to foster the knowledge exchange between both organisarions. In that sense, it was necessary to analyse the relationship between Company Maturity Models and knowledge management in an intercompany context.

In Edwards (2008), a review of knowledge management practices in the energy sector is presented. Approaches differ between different industries and oil sector is seen as a leader in knowledge management practice. In several Oil\&Gas companies, facilitating knowledge exchange between employees has provided the central thrust of their knowledge programs (Grant, 2013). This is one of the main interests of CoMMs.

Nonaka and Takeuchi (1995) proposed a model of knowledge creation based on four ways of knowledge combination and conversion that happen in companies when knowledge is created. Tacit and explicit knowledge and the processes of combining them are the key for knowledge creation.

A key contribution to knowledge management were established by Davenport and Prusak (1998). They propose a definition of knowledge as "a fluid mix of framed experience, values, contextual information, and expert insights that provides a framework for evaluating and incorporating new experiences and information. It originates and is applied in the minds of knowers".

Wenger (1999) proposes that organizations should make efforts to become as social learning systems and foster communities of practice as a group of by people who engage in a process of collective learning.

Considering the review of the literature, the possibility of using CoMMs in order to foster the knowledge creation in a supplier development context is something worth to be analised.

\section{Process Followed}

\subsection{CoMM Construction Process}

CoMM construction process consists in deploying the strategic targets of the company to the process to be analyzed. In the case described in this article, the question to be answered was "How can the Supplier Development Process contribute to achieve some of the main strategic targets?"

To answer to this question, several steps have been necessary (Figure 1). The main interest to develop a Company Maturity Model based on the knowledge existing in a company is to guarantee the coherence between the improvement axes that are analyzed and the specific strategy to be implemented. For instance, two companies operating in the same sector could define different maturity grids depending on the particular strategies they want to pursue.

To guarantee such a coherence in this project, a target deployment was necessary starting with strategic objectives, following with industrial objectives, to finally establish the goals to be achieved by the suppliers. This process was carried out with the participation of people representing several departments of the company as operations, maintenance, and purchasing. As the view was not always the same, it was necessary in several steps of the deployment to agree about the targets to be achieved by the supplier.

The next step was the selection of the suppliers to start with. The question to answer was the following one: "Taken into account the large number of suppliers cooperating with the company, which are the ones that could more strongly contribute to the achievement of the strategic goals defined for the company?" 


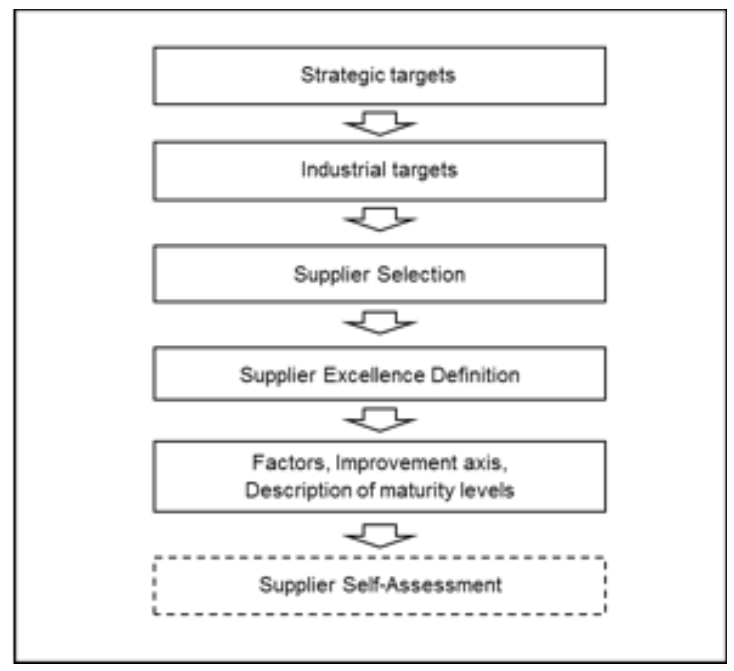

Figure 1. Company maturity model construction process

In this project, from the large number of existing suppliers, 760 local suppliers were preselected. Then, using a prioritization $A B C$ analysis, 40 suppliers were defined and, after several multidisciplinary contrast groups with employees of the company, three maintenance service suppliers were selected as the most capable to impact on the goals of the company.

The following step consisted in defining the improvement criteria to comply with by the maintenance service contractors, as well as the best basic tools, the technologies and the management methods that could be potentially implemented.

This process needs imperatively the participation of employees representing several departments such as operations, maintenance, purchasing, innovation, etc. They played a key role defining the minimum service level to be provided by maintenance service suppliers and the expected improvements necessary to achieve the defined goals. The maturity grid should represent the best of the knowledge existing inside the company, complemented with the expertise of external professionals and international benchmarking organizations. Among others, maturity grid was enriched by sources such as best practices of Oil\&Gas sector or others as automotive, aeronautics or nuclear sectors, comparative reports of company's performance to other companies of the same sector, satisfaction surveys from purchasing department concerning the quality of service and security and environment management behavior.

This allowed to transmit the criteria of excellence the company expects from the supplier which will be the reference for the self-assessment process.

The resulting maturity grid obtained is composed by 11 assessment factors that integrate the service provided by the supplier grouped in 5 fields: Management of the activities, Maintenance means, Proactivity, Employees and Results.

For each one of the factors, four levels of maturity were defined from level 1 (describing the minimum level the supplier should comply with to continue cooperating with the company) to level 4 (describing a high level of excellence of the supplier's service). Each one of the maturity grid levels was described using the specific vocabulary of the sector and the company in such a way so that the concepts, departments and vocabulary were easily understandable by the assessment group participants. 


\subsection{Supplier Self-Assessment Process}

In Figure 2, the process followed for the self-assessment of the supplier is presented.

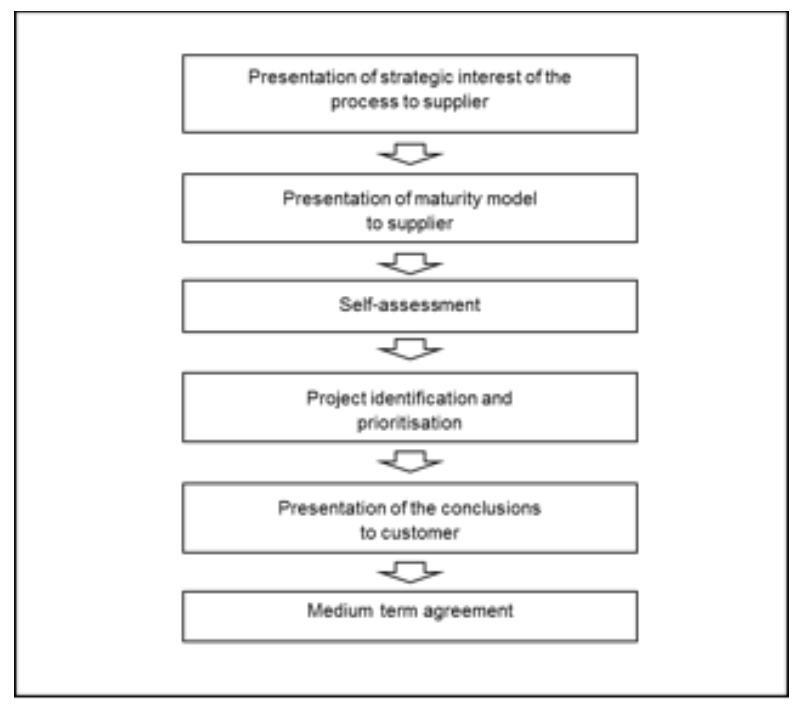

Figure 2. Self-assessment and project definition process

Once the maturity grid defined and approved, a meeting between the company and the supplier took place to propose the assessment process. During that meeting, the strategic purpose of the supplier development process, the competitive context of the company, the main improvement axes, a summary of the maturity grid and the role that the supplier could play were presented.

Once the agreement of the supplier to cooperate was confirmed, a group of contractor's staff between 6 or 10 members with a general vision of the service provided was formed to participate in the process. Self-assessment took place in three sessions of four hours each and were facilitated by the authors. During the sessions, after a brief description of the context, the group analyzed the service provided comparing it to the description established in the maturity grid.

For each one of the factors, the group members took some minutes to consider the level of the service provided, the evidences that demonstrated it and the actions that should be taken in order to be evaluated in a higher level. Then, for each one of the factors, each member presented his assessment to the group and the level where the service should be located was agreed after a procedure of sharing all participants' point of view about the level and potential action plans.

Once the assessment of the eleven factors accomplished, the group agreed on the main projects, gathering together the action plans identified, and prioritized them using a multicriteria matrix tool. The impact on strategic goals of the customer was the main criterion. A document for each one of the projects, describing the main targets, the responsible organization and department, the phases and main dates, the estimated cost and the expected benefits of each project, was elaborated.

During a meeting for the presentation of results between the customer and supplier companies, the conclusions of the process were presented and a medium-term agreement document was prepared to allow the execution of the projects, the necessary investments and the financing plan. 


\section{Results of the Self-Assessment Process}

The self-assessment process took place between July and December 2016 in three maintenance service suppliers. The field of activity of all suppliers was always the maintenance services but in different specialties and the maturity grid was the same. As specific results of the process, the following ones could be indicated:

- An excellence profile of the services provided by the contractor to the customer in each of the analyzed domains. The performance level in each one of the factors with evidences, action plans and other generic comments, the estimated impact on strategic targets of the customer and a very concrete project road map are included in an output document of the process for each one of the contactors.

- 137 potential action plans and 16 prioritized projects plans to improve the level of service of contractors and a budget for each one of the organizations as well as an estimation of the ways to finance.

It's important to indicate the high level of agreement between the assessment made by the supplier company and the perception of the customer company about the excellence level of the provided maintenance services.

As additional result, the supplier gets a very clear understanding of the customer's challenges allowing its employees to focus on the veritable strategic factors affecting the services provided. It answers to the question "how is my company affecting to the future of my customer?" The resulting maturity grid can be used by the contractor to train employee groups or new recruitments. Finally, a medium-term relation agreement between the customer and contractor is signed protecting from the entry of new competitors.

\section{Discussion and Conclusions}

In this paper, we have reported the application in three real cases of a CoMM created for the specific needs of a supplier development program of an Oil\&Gas company. CoMM could be defined as a maturity model designed by a company using its own main key factors, levels coherent with the strategy and vocabulary with the intention of assessing the maturity of a specific process and aiming to define the main projects to improve it. CoMMs are part of the knowledge and the culture of a firm and they include the management targets of the company.

In contrast to other maturity models (CMMI, EFQM, BPMM, PEMM, etc.), CoMMs include a very specific knowledge of the company and of the sector where it operates, and are influenced by the strategy and the culture of the company. Due to that specificity, CoMMs have not been studied as thoroughly as standard models.

During the project, the potential positive impacts and contributions of CoMMs as the following ones have arisen clearly and have been shared by the participants in the process.

- CoMMs have shown the capacity to extract knowledge from the supplier and translate it in a medium term strategic project road map that allows a win-win framework for both organizations.

- CoMMs allow to define and formalize the expectations of customers towards the supplier by making them explicit and clear. These can be written using the specific vocabulary of the company and of the sector, making it more understandable. This contributes to feed the knowledge creation spiral, making explicit the existing tacit knowledge (externalization) and combining explicit knowledge (combination) as proposed by Nonaka and Takeuchi (1995).

- CoMMs integrate in a single document the knowledge existing in different departments and experts inside or outside the customer company. The design of the maturity grid is a participating process with employees from different departments of the company, thus, allowing a learning process as it is described by Lave and Wenger (1990) in their situated learning theory.

- The process of group self-assessment contributes to the sharing of knowledge between representatives from supplier companies' different departments. This can be a source of new opportunities to propose more value to the customer. 
- CoMM assessment activities can be assisted by employees from the company. Team management and facilitating competences can help. In the cases described in this article, the process was enabled by the authors.

- Knowledge can be shared very easily inside the organization and with new potential suppliers. The contents of the maturity model grid could be included in the technical specifications of following contracts.

Of course, the quality of the CoMM is a key issue that must be undertaken with care. The design process of the maturity grid must be validated by different staff of the company. Even more, CoMMs should be reviewed periodically and the improvement possibilities detected during the application should be included. In projects as the one presented in this article, CoMM review should cover knowledge coming from comments made by the suppliers during the self-assessment process. Suppliers operate in different sectors, and that could represent a source of new technologies or management methods interesting to be integrated in the company.

CoMMs are tools to improve the excellence level of a company. In order to construct the maturity model, the best available know how in the company should be introduced in the grid coming from theoretical knowledge and the experience of employees who are consulted. Management decisions are often taken based only on manager's knowledge and experience.

The authors have observed that the steps followed to design and apply the CoMM respond to SECI process of knowledge creation proposed by Nonaka and Takeuchi (1995) contributing to a more innovative environment, specially, in an intercompany context as it is shown in the Table 1.

\begin{tabular}{|l|l|}
\hline \multicolumn{1}{|c|}{ SECI phase } & \multicolumn{1}{c|}{ Contribution of CoMMs } \\
\hline Externalization & $\begin{array}{l}\text { During the CoMM design, employees from the company and external experts contributed to the view } \\
\text { of the service demanded to contractors. The explanation of the strategy of the customer to the } \\
\text { supplier externalized a key knowledge that was tacit until then }\end{array}$ \\
\hline Combination & $\begin{array}{l}\text { To obtain a coherent CoMM, the view of different departments was combined. A balance was } \\
\text { necessary between contradictory views and the final model is documented in the CoMM report }\end{array}$ \\
\hline Internalization & $\begin{array}{l}\text { During the self-assessment process made by the contractors, members of the groups raised their } \\
\text { awareness of what was needed to be an excellent supplier and integrated it in their thoughts and } \\
\text { reflections }\end{array}$ \\
\hline Socialization & $\begin{array}{l}\text { After a reflection on the maturity level of the service provided by the participating suppliers and the } \\
\text { action plans needed to improve it, a socialization process in the network of contractors has occurred } \\
\text { through informal contact and sharing experiences. }\end{array}$ \\
\hline
\end{tabular}

Table 1. Contribution of CoMMs to SECI knowledge creation spiral proposed by Nonaka and Takeuchi (1995)

As Ramanigopal (2012) notes about knowledge management in Oil\&Gas sector, "organizations should provide opportunities to leaders to share their knowledge at their level and also to create new one". Organizations should become experts in capturing knowledge. CoMM is an efficient way to achieve this goal.

Moreover, the process followed in this project matches with the set of criteria and expectations needed by which the membership to a community of practice is recognised (Wenger, 2012), for instance:

- Understanding what matters, what the enterprise of the community is and how it gives rise to a perspective on the world.

- Being able (and allowed) to engage productively with others in the community.

- Using appropriately the repertoire of resources that the community has accumulated through its history of learning. 
Finally, research about the specificities of CoMM design, its application in different fields of a company such as management in a minifactory model context, quality management, security management and others, and the contribution to knowledge management should be fostered.

\section{Declaration of Conflicting Interests}

The authors declared no potential conflicts of interest with respect to the research, authorship, and/or publication of this article.

\section{Funding}

The authors received no financial support for the research, authorship, and/or publication of this article.

\section{References}

Becker, J., Niehaves, B., Pöppelbuß, J., \& Alexander, S. (2010). Maturity Models in IS Research. Pretoria.

Biberoglu, E., \& Haddad, H. (2002). A survey of industrial experiences with CMM and the teaching of CMM practices, Journal of Computing Sciences in Colleges, 18(2), 143-152.

De Bruin, T., Freeze, R., Kulkarni, U., \& Rosemann, M., (2005). Understanding the Main Phases of Developing a Maturity Assessment Model. ACIS 2005 Proceedings. Paper 109.

Crosby, P.B. (1979). Quality is free: The art of making quality certain. New York, NY: McGraw-Hill Companies.

Davenport, T.H., \& Prusak, L. (1998). Working knowledge: How organisations manage what they know. Boston, Mass: Harvard Business School Press.

Edwards, J.S. (2008). Knowledge management in the energy sector: review and future directions. International Journal of Energy Sector Management, 2(2), 197-217. https://doi.org/10.1108/17506220810883216

Grant, R.M. (2013). The development of Knowledge Management in the Oil and Gas Industry. Universia Business Review, 40, 92-125.

Hammer, M. (2007). The Process Audit. Harvard Business Review, 85(92), 1-17.

Lave, J., \& Wenger, E. (1990). Situated Learning: Legitimate Peripheral Participation. Cambridge, UK: Cambridge University Press.

McCormack, K., \& Lockamy, A., (2004), The development of a supply chain management process maturity model using the concepts of business process orientation. Supply Chain Management: An International Journal, 9, 4, 272-278. https://doi.org/10.1108/13598540410550019

Maier, A.M., Moultrie, J., \& Clarkson, P.J. (2012). Assessing Organizational Capabilities: Reviewing and Guiding the Development of Maturity Grids. IEEE Transactions on Engineering Management, 59(1). https://doi.org/10.1109/TEM.2010.2077289

Mettler, T. (2011). Maturity assessment models: a design science research approach. Int J Society Systems Science, 3(1/2). https://doi.org/10.1504/IJSSS.2011.038934

Nonaka, I., \& Takeuchi, H. (1995). The knowledge creating company: How Japanese companies create the dynamics of innovation. New York: Oxford University Press.

Paulk, M.C. (2008). A taxonomy for improvement frameworks. Proceedings of the World Congress for Software Quality. Bethesda, MD.

Pérez-Mergarejo, E., Pérez-Vergara, I., \& Rodríguez-Ruíz, Y. (2014). Modelos de madurez y su idoneidad para aplicar en pequeñas y medianas empresas. Ingeniería Industrial, XXXV(2), 146-158.

Ramanigopal, C.S. (2012). Knowledge Management for the Oil and Gas Industry: Opportunities and Challenges. Asian Journal of Business and Economics, 2(2.4 Quarter IV). 
Rosemann, M., \& de Bruin, T. (2005). Towards a Business Process Management Maturity Model. Proceedings of the ECIS. Regensburg, Germany.

Wenger, E. (1999) Communities of practice: learning, meaning, and identity. Cambridge University Press, New York.

Wenger, E. (2012). Communities of practice and social learning systems: the career of a concept. Available at: http://wenger-trayner.com/resources/publications/cops-and-learning-systems/ (Accessed: September 2017).

Journal of Industrial Engineering and Management, 2018 (www.jiem.org)

\section{(1) $(9$}

Article's contents are provided on an Attribution-Non Commercial 4.0 Creative commons International License. Readers are allowed to copy, distribute and communicate article's contents, provided the author's and Journal of Industrial Engineering and Management's names are included. It must not be used for commercial purposes. To see the complete license contents, please visit https://creativecommons.org/licenses/by-nc/4.0/. 